\title{
EMERGÊNCIAS GLOBAIS DO CLIMA: SOBERANIA E A GEOPOLÍTICA AMBIENTAL SUL-AMERICANA
}

\section{Global climate emergencies: sovereignty and South American environmental geopolitics}

\section{Elany Almeida de Souza ${ }^{1}$}

\section{Introdução}

A governança global do meio ambiente gradualmente tem se tornado pauta na agenda dos países. Essa discussão perpassa necessariamente pela Amazônia, em especial por sua sociobiodiversidade mundialmente conhecida e sua relevância em termos geopolíticos, geoestratégicos e geoeconômicos. As emergências globais do clima, entendidas como a gravidade representada pelo aquecimento global e pela ameaça que o desequilíbrio ambiental pode oferecer para a sociobiodiversidade, têm aspecto global porque os problemas ambientais não se limitam às fronteiras físicas ou imaginárias (espaço ou território) e têm impacto direto à soberania dos países. A imbricação entre o que hoje se entende por emergências globais do clima e a necessidade da adoção de uma perspectiva da geopolítica Sul-Americana, como lente de análise para as questões ambientais, se dá exatamente no sentido de enfatizar a importância do protagonismo dos países amazônicos, quando o assunto é governança ambiental.

Isso porque a securitização e dessecuritização da Amazônia já comportou ao longo da história diversos discursos e em diferentes matizes. Nesse sentido, importante investigar como construções discursivas instigam processos de securitização das questões ambientais, que em regra, são pautados por uma única narrativa, alçando um tema da agenda de low politics para a de segurança de high politics. É nesse aspecto, que se torna primordial que sejam discutidos, pelos e para os países amazônicos, caminhos que os coloquem como atores determinantes na elaboração e aprimoramento de mecanismos para o tratamento de questões acerca do desenvolvimento, sustentabilidade e proteção da sociobiodiversidade. Elementos que são

\footnotetext{
${ }^{1}$ Doutoranda em Ciências Militares pela Escola de Comando e Estado-Maior do Exército (ECEME). Mestre em Direito pela Universidade Federal de Santa Maria (UFSM). Bacharel em Relações Internacionais pela Universidade Federal de Santa Maria /UFSM. Especialista em Direito Civil e Metodologia do Ensino Superior pela Universidade do Sul de Santa Catarina/UNISUL. Bacharel em Direito pela Faculdade de Rondônia (FARO). Email: elanyalmeidas@gmail.com
} 
centrais em debates de nível regional específicos, eis que apresentam dinâmicas de seguranças próprias e por isso requerem soluções conjuntas.

Essa análise tem como pano de fundo os processos de securitização no continente sul americano, que foi enfatizado com o combate às drogas e ao narcotráfico e reforçado pela guerra global ao terror pós 11 de setembro de 2001. O tratamento da questão ambiental, sob a perspectiva regional e de segurança, pretende apontar, ainda, a importância do regionalismo nesse esforço, em especial entre países que têm elementos em comum: a sociobiodiversidade e a necessidade de sua preservação e defesa.

Trazer à essa discussão a possibilidade de construção de um complexo de segurança regional é propor uma cooperação em regiões de fronteira, com fundamento em uma política externa que vise a integração do continente e projeção internacional a partir da proteção da sociobiodiversidade da Amazônia. A fim de conduzir a pesquisa, adotou-se uma abordagem sistêmica. Como procedimentos, foram eleitos a pesquisa bibliográfica e documental. Como técnica, a construção de resumos e fichamentos da literatura interdisciplinar que trata do tema, dentre eles autores que enfrentam a problemática sob a perspectiva da Geopolítica Sul-Americana, Estudos de Segurança e Defesa, Estudos Estratégicos e das Relações Internacionais.

O presente trabalho apresenta-se em três momentos distintos. Inicialmente, far-se-á uma breve análise acerca da securitização e seus reflexos na questão ambiental. Em seguida, delinear-se-á um panorama de como ocorre a securitização da região sul-americana, seus principais focos e agendas e como esses esforços regionais poderiam ser incrementados a partir do Conselho de Defesa Sul-Americano. Esse, como fórum capaz de pensar estratégias e convergir os interesses nacionais e regionais, como a proteção e defesa da sociobiodiversidade. Não somente dar respostas às agendas globais (Guerra ao Terror e guerra às drogas), mas propor a formação de um Complexo Regional de Segurança na América do Sul.

Por derradeiro, uma abordagem da temática a partir da perspectiva da geopolítica ambiental SulAmericana, para discutir a necessidade de uma agenda regional que fomente mecanismos regionais de cooperação e defesa da sociobiodiversidade da Amazônia. E assim, reafirmar a importância da OTCA (Organização do Tratado de Cooperação Amazônica), como espaço de diálogo próprio para a construção de soluções conjuntas que corresponda às necessidades dos países amazônicos. Em considerações finais, demonstra-se a importância do protagonismo dos países amazônicos na gestão da Amazônia, diante do contexto de justaposição de atores e agendas que refletem mecanismos de projeção de poder e que se reinventam a cada nova ameaça de mudança estrutural e reorganização do equilíbrio de poder no sistema internacional.

\section{A securitização e seus reflexos na questão ambiental}

A securitização ambiental apresenta algumas agendas específicas de ordem global e, dentro de uma abordagem mais micro, encontra assimetrias regionais e/ou diferenças que fazem com que o tratamento seja mais ou menos intenso. No caso da Amazônia cabe uma atenção maior, sobretudo quanto aos discursos de securitização e internacionalização da mesma em detrimento da soberania dos países que a detém. Conforme demonstra o mapa abaixo, os países que compõem a Amazônia internacional são Bolívia, Brasil, 
Colômbia, Equador, Guiana, Peru, Suriname e Venezuela e Guiana Francesa, porém, esse último, não integra a Organização de Cooperação do Tratado de Cooperação Amazônica - OTCA.

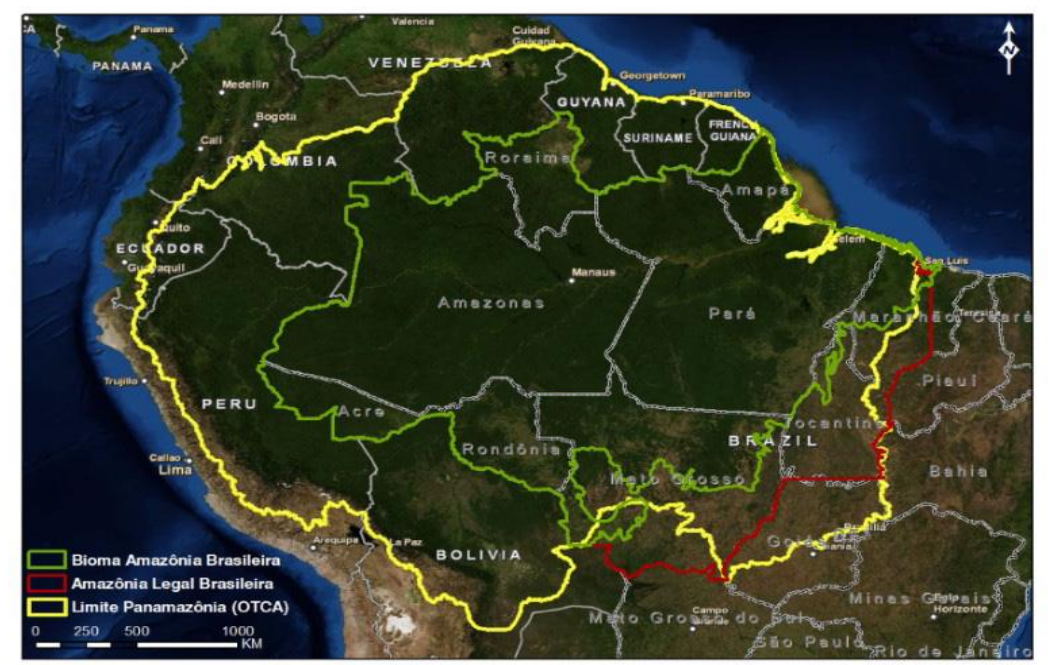

Fonte: Mapa da região Pan-Amazônica (RESK, 2019).

O que se propõe no tocante à temática ambiental e em relação à Amazônia, é uma abordagem contextualizada, que leve em conta as diferenças de perspectivas política, de segurança e de defesa, bem como especificidades locais e regionais. À análise de como a agenda de securitização ambiental tem sido posta, importa se apropriar do que há de não oficial na relação entre o agente securitizador e o objeto securitizado (SOUZA, 2018). Isso porque a abordagem discursiva entende que a "segurança não pode ser definida em termos objetivos e que, portanto, tanto as concepções objetivas quanto as subjetivas são enganosas" (BUZAN e HANSEN, 2012, p. 68).

No campo dos estudos de segurança internacional, há que se verificar epistemologicamente de início a "distinção entre as concepções objetivas, subjetivas e discursivas de segurança” (BUZAN e HANSEN, 2012, p. 67). Os Estudos de Segurança Internacional sob a perspectiva da Escola de Copenhague têm como objetos de referência a coletividade e o meio ambiente. Sob esse prisma, se tem como epistemologia o ato da fala, sendo através dele possível identificar visões da política de segurança, os setores envolvidos, os níveis de ameaça, se internos ou externos (BUZAN e HANSEN, 2012).

Perquirir sobre a securitização ambiental, em específico a partir e para os países amazônicos, importa visitar debates travados nas Relações Internacionais e no âmbito do Realismo Político. Esse, “constrói cenários em que o conceito de securitização (ato de fala) é o que letigima a securitização do objeto e, por consequência, legitima intervenções e ingerências ecológicas” (SOUZA, 2018, p. 4). Isso porque “A construção discursiva de "ameaças à segurança” será influenciada pela história de um Estado, sua posição geográfica e estrutural, além das reações (discursivas) que obtém de outros, internacional ou domesticamente" (BUZAN e HANSEN, 2012, p. 69).

O importante em distinguir os elementos que compõem a variável discursiva, implica diretamente em considerar os limites da abordagem teórica, eis que quando trazidos a dialogar com outras variáveis, podem alterar a avaliação do agente securitizador, bem como de sua audiência. Como, por exemplo, as 
relações hierárquicas de poder no cenário internacional, as dicotomias 'colonizador x colonizado', 'norte x sul', os desacordos culturais, 'desenvolvimento x sustentabilidade'. São elementos que auxiliam na melhor compreensão de como questões são levadas ao patamar de políticas de segurança e/ou defesa. Quando a análise parte de pré-compreensões universalistas, as armadilhas estão postas, uma vez que a própria teoria deixa de aprofundar e problematizar outras variáveis, a lente de observação se torna míope (SOUZA, 2018).

Ao acrescentar outras variáveis à teoria de securitização, ela continua a ter o mesmo viés explicativo e justificador, ou pode revelar outra vertente? Essa avaliação deve ser feita no contexto das políticas globais e como o tratamento das mudanças climáticas tem sido conduzido e eleito como tema relevante da agenda de segurança internacional. Em especial, compreender a debilidade dos mecanismos de soft law (Convenção da Biodiversidade, por exemplo) frente aos de hard law (mercado) e a implicação direta na ineficiência das políticas de governança global em matéria ambiental.

Assim, denota-se que a Escola de Copenhague oferece uma lente de observação da securitização ambiental e como medidas tangenciais ao arcabouço normativo podem ser instrumentalizadas. Contudo, é somente com os estudos regionais que se permite perceber a limitação de teorias clássicas que preconizavam uma "leitura de uma realidade internacional em que a insegurança e a competição impediam iniciativas de cooperação" (TANNO, 2003, p. 49). Cabe ainda considerar que, "as concepções teóricas tradicionais das relações internacionais só alcançam até determinado ponto na explicação da problemática ambiental atual” (GEHRE, 2009).

Aliás, Barry Buzan desde os anos 90 já entendia que a análise isolada de setores e atores não seria suficiente para compreender e conceituar a segurança internacional. Para isso, partia da premissa que só uma ideia inclusiva e que permeasse as diversas especificidades regionais, seria capaz de dar um diagnóstico do quadro da segurança internacional. No final da década de 90 WAEVER et al. (1998) passam a afirmar que:

Segurança é o movimento que trata a política para além das regras do jogo estabelecidas e enquadra a questão, ou como um tipo particular de política, ou como algo que a transcende. [...] Segurança é, assim, uma prática auto-referida porque é no contexto desta prática que se torna uma questão de segurança - não necessariamente porque haja uma ameaça existencial real mas porque é apresentada como ameaça (WAEVER et al., 1998, pp. 59-60).

Importante ressaltar que o "foco da opinião pública mundial tem despertado diferentes formas de discursos securitizadores, e levou o debate sobre a Amazônia do campo da política para o campo da segurança” (URT e PINHO, 2010, p. 34). Esse cenário teve a Amazônia como objeto de referência em momentos distintos da história mundial, pois após a $2^{\text {a }}$ Guerra (1939-1945), com a perda do caráter estratégico da borracha para a indústria bélica, a relevância diminuiu consideravelmente. Contudo, a Amazônia volta aos palcos de discussão por ocasião da Conferência das Nações Unidas para o Meio Ambiente em 1972 em Estocolmo.

Desde então, a adesão de países aos acordos e convenções internacionais dos vários temas ambientais aumentou e houve grande mobilização para a formulação de conceitos operacionais da ordem ambiental internacional, como os de desenvolvimento sustentável e de segurança ambiental global. Esse último, entendido como o conjunto de estratégias que objetivam alcançar as condições necessárias para a 
reprodução de todas as formas de vida. Consolidados em regras internacionais que implementam políticas globais aptas a evitar catástrofes ambientais e asseguram a manutenção e a reprodução da ordem de poder mundial já existente (RIBEIRO, 2001).

Os debates passam então a girar em torno de como a governança do meio ambiente tem sido levada à sério, ou não, pelos países. Em especial, como é operada a gestão dos recursos naturais, para questionar em alguns momentos a capacidade de gestão pelos países que os possuem. Miyamoto (2010) recorda que o Relatório Brundtland apresenta a ideia de necessidade de soberania compartilhada ou de soberania limitada, o que demonstra que há uma espécie de consenso na sociedade internacional de que a governança ambiental dos países amazônicos não necessariamente estaria sob uma única e exclusiva responsabilidade.

Trata-se de um dilema de securitização ambiental que gera uma sensação de insegurança pelos setores político e militar e uma falsa ideia de que há uma falha ou má gestão do objeto securitizado (SOUZA, PINTO, SOUZA, 2017). Assim, ensejariam medidas excepcionais, como abertura para ingerências ecológicas e relativização de soberania, afirma Bachelet (1995). Conforme alertam Souza et al. (2017), os mecanismos que ativam os processos de securitização são disparados conforme a percepção de ameaça se mostra latente. No caso da questão ambiental chamam atenção para o que Boeno et al. (2015) aludem ao demonstrar que em 2015 as alterações climáticas foram elevadas ao mesmo nível de ameaça que armas de destruição em massa e ataques terroristas, passando a compor a agenda da National Security Strategy of United States of America. Traz assim, para o campo da segurança a temática ambiental, inclusive como objeto de deliberação pelo Conselho de Segurança das Nações Unidas.

Nesse sentido, vale recordar que as ameaças de ingerências ocorrem, não por expressão de hard power, mas sim pela influência exercida pelas grandes potências. Ou seja, "não mais visa a apropriação direta dos territórios, mas sim o poder de influir na decisão dos Estados sobre seu uso” (BECKER, 2007, p. 34). Diante desse cenário, denota-se a importância da percepção que o continente sul americano possui dinâmicas de seguranças próprias e por isso reclama um tratamento a partir de suas específicas necessidades.

É o que será tratado a seguir, em especial para demonstrar, em breves linhas, como tem ocorrido a securitização da região sul americana, seus principais focos e agendas e, ao final, alertar para a necessidade de um esforço regional de defesa e proteção da sociobiodiversidade por meio de um Complexo Regional de Segurança na América do Sul.

\section{A regionalização da securitização na América do Sul a necessidade de um concerto regional na proteção da sociobiodiversidades}

À luz do que preconiza Aron (2006), aos interessados em saber quais as porosidades que envolvem o contexto de paz ou guerra entre as nações, é imprescindível investigar as regularidades históricas, os padrões de comportamento, bem como os incidentes decorrentes da atuação dos países em determinado contexto histórico. Essas premissas são plenamente aplicáveis ao contexto da região sul-americana.

No tocante à regionalização da securitização na América do Sul, questões elevadas ao nível da segurança internacional têm, por consequência, a atuação militar de grandes potências na aplicação de 
medidas emergenciais e excepcionais. Não tem sido diferente no continente sul-americano, pois, ainda que a região não tenha sido palco, nos últimos anos, de conflitos em âmbito global, algumas questões específicas têm causado preocupação à medida em que podem ter efeitos transnacionais, como no caso do narcotráfico e do terrorismo.

Nesse sentido, Villa (2013) identifica que na América do Sul a securitização tem correspondido às novas formas de operacionalizar presença militar dos EUA. Essa, combina o atendimento às necessidades decorrentes de percepções de ameaças de cada Estado à vontade política dos EUA de se fazer presente, seja por ações militares com viés humanitário ou até mesmo em auxílio às nominadas guerra às drogas ou Guerra Global ao Terror. A estratégia hemisférica reside em adequar percepções de ameaças não territoriais e alocar novas bases militares, ou Forward Operation Locations (FOLs), com vista a explorar motivações não tradicionais. Isso decorre da mudança de percepção de ameaça Pós-Guerra Fria, que deixa de ser apenas territorial e passa a ser transfronteiriça, como é o caso do terrorismo, narcotráfico entre outros. Assim, há uma inversão nos papéis das agências de segurança (polícia) que por vezes adotam a função de defesa, e as agências de defesa (forças armadas), que passam a ter também função de segurança (VILLA, 2013).

O conceito de segurança multidimensional não só coloca no mesmo nível de segurança questões (terrorismo, narcotráfico, migrações) que por sua natureza, origem e consequências devem ter tratamento diferentes, como também sugere que é da competência das forças armadas a solução desses problemas, o que transforma uma agência de defesa em uma de segurança. Essa mudança de perspectiva traz consigo a estratégia da política externa americana, que passa buscar novas alternativas para viabilizar a presença militar dos EUA e avoca para si a responsabilidade da guerra às drogas e da Guerra ao Terror. O resultado é não só a presença militar, como também a instalação de várias bases na América Latina (VILLA, 2013).

A instalação das FOLs se dá por meio de acordos de cooperação com os estados hóspedes, em específico aqueles conhecidos como zonas de trânsito e zonas de fontes de drogas (Caribe, América Central, Pacífico Norte e América do Sul). Elas atuam com a permissão dos governos hóspedes e ampla proteção dos militares e equipamentos, além de imunidade diplomática para militares e civis americanos (extremamente questionável do ponto de vista da responsabilização e accountability) e fornecimento de infraestrutura. Outros mecanismos, inclusive normativos, também são utilizados para validar e legitimar a retórica da guerra às drogas e ao terror, que podem ampliar o escopo de ações e tarefas conjuntas. Nesse conjunto de ações, interesses de segurança nacional se misturam a interesses privados, de modo que ingerências são operadas a partir da administração de empresas estatais de recursos naturais (VILLA, 2013).

Rodrigues (2012), a respeito, chama atenção para o fato de que o vetor biopolítico perpassa várias políticas públicas não só no norte global, mas também é adotado por todo o mundo, inclusive na América Latina, seja por meio de participação em acordos bi e multilaterais, bem como na ratificação de tratados comprometidos com o tema. Resulta daí um regime internacional de controle às drogas que tem como fundamento a existência de um consenso global de que essa é uma guerra de todos, porque seus efeitos são transnacionais. Esse consenso atualmente vem incrementado pela Guerra ao Terror, que traz semelhanças tão latentes resultantes em interpretações simplistas que desaguam no mesmo maniqueísmo e 
reducionismo securitizadores e/ou macrossecuritizadores de questões nacionais e regionais, de modo a justificar medidas extremas de efeito global (RODRIGUES, 2012).

A busca por consenso e o sucesso na macrosecuritização apontam para um respaldo regional e local na securitização do tema guerra às drogas. O discurso macrossecuritizador é global, porém necessita de um lastro e contexto local/regional que o legitime, do contrário o efeito pode não ser exatamente o esperado. Estar-se-ia, portanto, diante do que Villa (2014) denomina como o paradoxo da macrossecuritização e alerta que "a própria incapacidade de atores regionais sul-americanos em gerar agendas autônomas regionais de segurança contribui para o sucesso do discurso da macrossecuritização" (VILLA, 2014, p. 376). O autor chama ainda atenção para o fato de que negociações multilaterais e regionais atenuam os efeitos da securitização e também reduzem possíveis ingerências e intervenções por outros Estados ou organismos internacionais em assuntos locais.

Saint-Pierre (2011), nesse sentido, adverte o risco que é multidimensionar e/ou incorporar acriticamente conceitos e agendas hemisféricas de ameaças. Isso porque a segurança multidimensional mistura indiscriminadamente vários elementos de naturezas diferentes e que reclamam respostas diversas. Não considerar, eleger suas próprias agendas de interesses e assumir ameaças globais como locais e regionais, sem qualquer análise mais aprofundada das medidas emergenciais receitadas, são "claros sintomas de soberanias incompletas e consequências indesejadas de democracias deficientes" (SAINTPIERRE, 2011, p. 415).

Saint-Pierre (2011) ao deixar implícita a necessidade da descolonização do pensamento de defesa, diz que isso pressupõe "reconhecer seus próprios problemas, formular suas perguntas, burilar seus conceitos, ensaiar seus métodos e construir suas teorias com a precisão de quem não teme discutir com autonomia e universalidade seus resultados” (SAINT-PIERRE, 2011, p. 427). A possibilidade de formalização de arranjos cooperativos é consequência de particularidades históricas, demandas originais, percepções e vulnerabilidades específicas, bem como de condições institucionais próprias dos países e regiões. Esse é o cerne de iniciativas regionais na área da segurança como o Conselho de Defesa Sul-Americano, criado em 2008 como órgão pertencente à União das Nações Sul-Americanas - UNASUL (SAINT-PIERRE, 2013).

Tratar desses elementos no intuito de fomentar a formação de um complexo regional de segurança para a proteção e defesa da sociobiodiversidade é, à luz do que instrui Saint-Pierre (2013), conjugar interesses convergentes e buscar a construção de medidas de confiança entre as nações e fortificação do setor de defesa Sul-Americano. Isso porque permite identificar os fatores de ameaça e risco para a região e a articulação de políticas regionais em matéria de defesa e segurança, com o compromisso em construir uma “visão compartilhada de Defesa e Segurança Regional". "A construção de ideias e expectativas sulamericanas passa por um entendimento compartilhado de conceitos que, por sua vez, permitam operacionalizar a cooperação" por meio de uma identidade estratégica regional capaz de, cooperativamente, “defender a região, sua sociedade, suas riquezas culturais e naturais e a particular forma de ser sulamericana de eventuais cobiças estranhas à região" (SAINT-PIERRE, 2013, p. 300, 306 e 307). Gehre (2009, p. 89), a esse respeito, preconiza que é preciso dinamizar "uma diplomacia climática regional, suportada em interesses regionais e em instituições, como a OTCA e a UNASUL”. 
A ideia de cooperação ganha escopo e processos de integração regional e são levados a cabo, uns com menos ou mais sucesso, menor ou maior tempo de durabilidade. Hurrel (2007), nesse sentido, esclarece que um sistema de Estados preconiza uma cultura comum, o que exige certo grau de unidade. Assim, as necessidades endógenas ou exógenas dos países da região podem representar reflexos das pressões sistêmicas resultantes da distribuição internacional de poder. O enfrentamento dessa dinâmica determinará como esses fatores podem afetar ou contribuir para as relações entre os vizinhos. No bojo desse arcabouço teórico acerca do regionalismo, é importante refletir como a integração regional tem papel estratégico na conservação da sociobiodiversidade, bem como os documentos de defesa brasileiros versam sobre a temática ambiental. Da leitura dos documentos de defesa brasileiros, denota-se que:

\begin{abstract}
A defesa da soberania ambiental é intrínseca aos documentos de defesa brasileiros (Política Nacional de Defesa (PND), a Estratégia Nacional de Defesa (END) e o Livro Branco de Defesa Nacional (LBDN) e Livro Verde de Defesa (LVD)), que em sua maioria destacam de forma contundente e expressa, a importância que possui a Amazônia e seus recursos naturais para o país. Contudo, embora a interoperabilidade e atuação interagências em âmbito nacional sejam práticas cotidianas e resultados de políticas públicas no combate ao crime organizado transnacional, ao narcotráfico, crimes ambientais e demais crimes transfronteiriços, há uma assincronia no tocante a uma percepção epistemológica acerca da defesa e proteção da biodiversidade. Essa assincronia se verifica pela ausência de iniciativas e parcerias regionais para a proteção da biodiversidade que confiram uma dimensão regional da defesa em matéria ambiental, bem como a existência de uma cultura estratégica de cooperação (smart power), que entendam o meio ambiente como ativo de poder no cenário internacional.

(...)

Essa lacuna cada vez mais vem sendo intensificada dada a distância de um concerto regional de integração, que por consequência inviabiliza que interesses, potencialidades e maximização de capacidades inerentes aos países detentores da Amazônia assim se percebam e sejam percebidos. A adoção de agendas de macrossecuritização em torno do combate ao narcotráfico e ao crime transnacional acaba por desviar o foco do que deveria ser a principal agenda regional de segurança $\mathrm{e}$ defesa (SOUZA, 2018, p. 4).
\end{abstract}

Verifica-se que, ainda que as disposições normativas destaquem a relevância da defesa da Amazônia e de seus recursos naturais, não se observam ações concatenadas e muito menos uma harmonia das políticas de defesa e das políticas externas que se coadunem com tais propósitos. Essa compreensão perpassa por fatores como rever e readequar às novas tecnologias políticas já consolidadas, como, por exemplo, a estratégia da presença, mas também perceber que os arranjos normativos e acordos regionais é que serão capazes de dissuadir interesses externos quanto à gestão dos recursos da região.

A importância estratégica da Amazônia brasileira chama atenção para fatores que levam à reunião de agendas em matéria ambiental na América do Sul, por meio da integração e cooperação, com geração de benefícios para o país e demais vizinhos fronteiriços. Fuccille et al. (2017, p. 64) alvitra que a Amazônia é fundamental para a articulação e integração da América do Sul, dadas suas "extraordinárias possibilidades e desdobramentos sobre o subcontinente, seja pelas limitações e preocupações que enseja, constituindo verdadeiro ponto nevrálgico da defesa dos recursos naturais da região." Note-se que "no âmbito da cooperação, a criação de convergência depende muito mais do compromisso político dos Estados-membros envolvidos, pois nem sempre há consenso...” (RODRIGUES, 2013, p. 56). Por isso, a proteção da sociobiodiversidade deve ser conduzida por meio de estratégias que considerem os interesses comuns, identidade e demais elementos de convergência (SOUZA, PINTO, SOUZA, 2017). Nesse sentido, 
"Transforma-se, assim, uma linha de fissura em cimento que liga duas nacionalidades e proporciona o desenvolvimento integrado" (CUNHA E MENEZES, 2015, p. 202- 203).

Assim, o regionalismo cognitivo é um dos caminhos, uma vez que é baseado em instituições de cooperação regional para fins de segurança e bem-estar, onde a identidade pode se dar através da interação mútua, semelhanças geográficas e interesses políticos e econômicos coincidentes (AYOOB, 1999). Por essa razão, políticas convergentes devem se amoldar aos contornos das ações externas, de modo a apontar caminhos para a formação de complexos regionais de segurança. Sobre o tema, Fuccille e Resende (2013) entendem que o Brasil tem papel centralizador dos dois subcomplexos sul-americanos (Norte-Andino e Cone-Sul) e por isso foi protagonista nessa constelação de segurança, uma vez que atuou como fiador na estruturação do Conselho de Defesa Sul-Americano (FUCCILLE, RESENDE, 2013). Nesse sentido, vale recordar que:

Complexos de segurança resultam da estrutura anárquica do sistema internacional moderno e consistem em estruturas anárquicas em miniatura ou subsistemas. Fazem parte, portanto, de um nível intermediário de análise, localizado entre as dinâmicas interestatais e sistêmicas de segurança (TANNO, 2003, p. 69).

Deve-se observar que a distribuição de poder, os padrões de interação entre os Estados, a interdependência entre suas relações e a classificação entre Estados fortes ou fracos, a depender da capacidade de projeção de poder, são os fatores determinantes na possibilidade de gerar complexos de segurança. Assim, não somente os Estados seriam os únicos atores capazes de gerar complexos, mas também as nações, os grupos ambientalistas e comunidades epistêmicas etc. (STRITZEL, 2007). Acerca do tema, importante frisar que:

Um complexo de segurança é definido como um conjunto de unidades cujos principais processos de securitização e dessecuritização, ou ambos, são tão interligados que seus problemas de segurança não podem ser razoavelmente analisados ou resolvidos de maneira separada (WÆVER et al., 1998 apud TANNO, 2003, p. 70).

Souza et al. (2017) salientam que pensar o território amazônico sob a perspectiva geopolítica e geoestratégica, além de fortalecer a defesa e segurança, também promove uma projeção internacional do país, na medida em que influencia e promove a integração regional por meio de medidas de infraestrutura, normativas, entre outras. Esse foi o cerne da Infraestrutura Regional Sul-Americana - IIRSA, quando propôs uma maior aproximação entre os países do entorno regional a fim de viabilizar a construção de uma perspectiva estratégica comum para mitigar possíveis dissensões na esfera da cooperação dos Estados e possibilitar o enfrentamento dos interesses externos que perpassam esse território (SANTOS, 2014).

O que traz grande preocupação atualmente está exatamente no vazio que a agenda diplomática brasileira trata as possibilidades de integração regional, inclusive a maneira como a UNASUL foi abandonada. Não só a posição de liderança brasileira nos aspectos voltados à região, bem como o afastamento da multilateralidade característica da política externa do Brasil, tem sido o comportamento vigente e com isso tem deixado de ocupar espaços tidos como cruciais. 
Lima (2005) e Pecequilo (2008) reforçam que ao Brasil cabe a posição e atuação efetiva alicerçada nas arenas multilaterais, uma vez que a ambição por exercer destaque e poder de influência junto às grandes potências sempre permeou a história e o pensamento da política externa brasileira, dada sua tradição global-multilateral. Esse vazio significa também afastar-se da posição de paymaster, que como cita Saraiva (2011), essa foi a tônica da liderança exercida pelos governos Lula na América do Sul, onde atuou para absorver os custos da integração e prover o coletivo de bens públicos necessário para o êxito dos processos de integração dos quais fez parte.

O governo Dilma já não deu a mesma atenção que foi dedicada nos mandatos de Lula (2003 a 2011), ainda que tenha mantido algumas premissas em seus primeiros anos, mas que perderam a amplitude até serem completamente abandonadas após impeachment, em 2016. Esse atual quadro é extremamente preocupante, porque em grande medida os caminhos para os mecanismos de cooperação haviam sido delineados desde a década de 1960, quando a importância da Amazônia fomentou novos contornos ao ser exposto seu potencial mineral, agrícola e energético (SOUZA, PINTO, SOUZA, 2017).

Nesse sentido, Santos (2014) rememora que foi nesse cenário que Brasil, Bolívia, Colômbia, Equador, Guiana, Peru, Suriname e Venezuela envidaram esforços de cooperação, o que resultou no Tratado de Cooperação Amazônica - TCA. Posteriormente com a criação da Organização do Tratado de Cooperação Amazônica - OTCA, teve como base a reafirmação da soberania estatal e o diálogo entre os países amazônicos que visavam promover o desenvolvimento sustentável (SANTOS, 2014).

A importância da percepção que a região em comento possui dinâmicas de seguranças próprias e por isso reclama um tratamento a partir de suas específicas necessidades, reafirma a necessidade de um complexo regional de segurança como mecanismo estratégico e eficaz na defesa e proteção da sociobiodiversidade. Esse é o papel do Brasil, por meio de uma liderança regional que precisa ser retomada e reiterada. São as iniciativas de concertos regionais e de cooperação estratégica, como a OTCA, que podem evitar o avanço de processos de securitização e macrossecuritização, bem como possíveis ingerências ecológicas de grandes potências e organismos internacionais com interesses alheios à região.

A próxima seção será dedicada a uma abordagem da temática a partir de uma perspectiva da geopolítica ambiental Sul-Americana, para discutir a necessidade de uma agenda regional que fomente mecanismos regionais de cooperação e defesa da sociobiodiversidade da Amazônia.

\section{Geopolítica Ambiental Sul-Americana: a agenda regional e os mecanismos regionais de cooperação e defesa da Amazônia.}

A Geopolítica, enquanto relação entre poder e espaço geográfico, é uma perspectiva de análise para diversas dinâmicas globais. No tocante aos países amazônicos, a geopolítica ambiental se torna imprescindível para compreender o lugar que ocupa não só geograficamente, mas principalmente do ponto de vista dos interesses e pressões políticas que recaem sobre a região. Por essa razão, é importante discutir as variáveis que influenciam diretamente na dificuldade reiterada em pensar e elaborar políticas públicas adequadas ao desenvolvimento e defesa da região amazônica, que atendam mais aos interesses endógenos que às demandas externas. 
Como abordado na seção anterior, a grande problemática em torno da questão ambiental na região reside em identificar qual a estratégia regional para a defesa do meio ambiente e conservação da sociobiodiversidade dos países amazônicos. Decorrência, talvez, do fato de que os problemas de segurança e defesa eleitos, pouco tangenciam a questão ambiental e quando o fazem, restringem-se às abordagens afetas aos crimes ambientais e transfronteiriços não como centro do problema, mas como consequência de outras redes de ilícitos como o narcotráfico e demais crimes transnacionais.

Fomentar mecanismos regionais de cooperação em defesa da Amazônia necessariamente remete à elaboração do Tratado de Cooperação Amazônica (1978) e à Organização do Tratado de Cooperação Amazônica - OTCA. A abordagem a partir da geopolítica como ferramenta analítica da questão ambiental permite compreender as nuances que permeiam as leituras políticas, geográficas e históricas em torno da temática ambiental. O termo "geopolítica" foi cunhado incialmente por Rudolf Kjellen (1899) com a preocupação quanto à influência da geografia e da política. A geopolítica passa a ter sua compreensão modificada a depender dos períodos históricos e a mudança das estruturas globais.

Interpretada a priori como conhecimento imperialista a serviço da política externa, no final da guerra fria, representou controle e influência sobre recursos estratégicos do mundo. Na década de 1970, seu significado passou a ser sinônimo de jogo de superpotência e equilíbrio de poder no cenário global. A geopolítica, portanto, pode ser compreendida como instrumento que confere dinâmica ao mapa político mundial, que relaciona a dinâmica regional ao sistema internacional como um todo indivisível (TUATHAIL et al., 2003).

Tucídides (2001), em a História da Guerra do Peloponeso, demonstra que a dimensão de poder de um Estado é manifestada não apenas por poder hard, mas também por meio de intenções e interesses externalizados por recursos de natureza soft, como a assinatura de tratados, acordos de cooperação, ameaça e/ou rompimentos destes. Essa dimensão sistêmica fornece uma perspectiva de análise do sistema internacional. Com isso, dinâmicas são impressas face às leituras geopolíticas que as potências fazem das regiões que possam lhes despertar interesses. Predizer os movimentos de poder e as possibilidades de cooperação, é o que se espera de atores que pretendem maximizar os ganhos e diminuir os custos que os riscos de conflitos podem gerar no tempo e espaço que ocupam (TUATHAIL et al., 2003).

Essa compreensão do tempo e do espaço é agora incrementada por influências tecnológicas pautadas por processos desencadeados em rede, permeados por fluxos de pessoas, bens e serviços que exigem novas abordagens, mas que não fogem à ferramenta analítica atemporal da geopolítica. A globalização e as demandas externas decorrentes dos fluxos de comércio, investimentos, cadeias globais de valor e buscas por recursos naturais ressignificam as noções de soberania e geografia. É por influência direta de aspectos geoeconômicos e geoestratégicos que se dá a imbricação da relação de interdependência e sobrevivência no sistema internacional, que não mais se limitam a conflitos de hard power, mas por forças transnacionais que impõem ameaças de diversas ordens (BECKER, 2007). Entre essas ameaças estão o terrorismo e o transbordamento de problemas ocasionados por conflitos externos de origem étnica, religiosa, ou até mesmo os desastres naturais. 
Como evoca Maria Regina Soares de Lima et al. (2017), a segurança ambiental, as mudanças climáticas e as variáveis que envolvem essa complexidade problematizam categorias de vulnerabilidade e risco do país e de sua população. Assim, dadas as assimetrias de poder na ordem global, as respostas precisam ser coletivas na medida em que entrecruzam questões de segurança, modelos de desenvolvimento e relações Norte-Sul. Nesse sentido, salienta que "a questão ecológica é especialmente importante para a política de defesa brasileira”, não só pela tradicional leitura histórica que a diplomacia do Brasil revela sobre a problemática ambiental, como também ao enfatizar que as responsabilidades para suas soluções devem ser comuns a todos. Ressalta ainda, a necessidade de assegurar a defesa de um crescimento sustentável, capaz de rejeitar teorias neomalthusianas, ou de crescimento zero, a serviço de uma imutabilidade da assimetria internacional de poder e adverte, por fim, que a proteção de ecossistemas já foi justificativa de ingerências ecológicas nos países amazônicos (SOARES DE LIMA et al., pg. 39, 2017).

Cabrera (2018) demonstra que o principal problema da perspectiva geopolítica sul-americana é que embora desenvolvida no âmbito dos estudos das Relações Internacionais, seu real conhecimento não tem sido aprofundado no tocante às reflexões teóricas com aplicação para a realidade regional. $\mathrm{O}$ autor entende que é necessário incorporar novos conceitos teóricos e epistemológicos que facilitem a difusão e entendimento dos interesses da região, que não se resumem aos interesses estritamente militares. Cabrera (2017) reitera que não é possível desenvolver um pensamento geopolítico regional com base em parâmetros externos e derivados de vivências anglo-saxãs, isto é, alheias aos problemas regionais. Ressalta ainda, o fato de que os problemas e processos os quais a região enfrenta não podem ser explicados por uma única matriz de pensamento (CABRERA, 2018). Nesse sentido, Tickner e Hertz (2012) advertem que deve haver um esforço necessário que considere as perspectivas críticas e interpretativas, típicas dos estudos estratégicos, que levem em conta o ponto de vista próprio da região.

Bruckman (2012) salienta que é imprescindível que se tome em conta, na concepção geopolítica regional, os interesses e perspectivas dos Estados Unidos, haja vista ser a potência militar e econômica do continente. Importante, portanto, dimensionar os interesses que a região desperta e o fato de que é na América do Sul que se encontra a Amazônia, com diversas fontes de água doce e demais recursos naturais. Cabrera (2018) aponta que não há na região uma consciência de proteção dos seus recursos naturais, tampouco a percepção de como atores extra regionais podem querer interferir na gestão dos referidos recursos. Por essa razão, a relevância geopolítica de fomentar mecanismos de gestão regionais e proteção dos recursos naturais é clara, uma vez que as posturas adotadas pelos países que compõem a região é que determinará os parâmetros de comportamento dos demais atores internacionais. Diante desse cenário, Cabrera (2018) assevera que: "Siendo así, la perspectiva de considerar los intereses de Estados Unidos en la región, la protección de los recursos naturales y el fenómeno del narcotráfico, son comunes denominadores a la hora de generar y construir un modelo de pensamiento geopolítico regional" (CABRERA, 2018, p. 188).

Como defendeu Becker (1995), o desenvolvimento na Amazônia depende de uma nova racionalidade tecnológica e científica onde o meio ambiente seja pautado pela inclusão da sociobiodiversidade e pelo planejamento territorial dos países que a compõem, mediante cooperação. Contudo, não só nas questões ambientais, mas em demais áreas que reclamam cooperação, o que se tem verificado é que os Estados 
progressivamente se isolam e deixam de atuar de forma cooperativa. As instituições anteriormente financiadas e pensadas para regular as relações entre os soberanos têm sido esvaziadas propositalmente e enfraquecidas em um verdadeiro (des)governo dos interesses. Essa também é a dinâmica imposta a diversas instituições como a UNASUL e, mais especificamente no tocante aos países amazônicos, à OTCA.

É dentro dessa relação 'homem - espaço geográfico - natureza - política' que se entende como necessário revisitar os fundamentos da OTCA à luz da geopolítica ambiental, para pensar o lugar e papel dos países amazônicos nas conversações políticas em matéria ambiental. O fortalecimento desse mecanismo de cooperação estratégica permite predizer quais os prováveis pontos de fricção frente ao cenário geopolítico mundial, bem como reestruturar as construções teóricas e práticas que fazem ainda da região uma zona de confluência de paz. Em tempos em que líderes mundiais questionam a validade dos estudos acerca das mudanças climáticas, outros avançam no sentido de se preparar para lidar com as adversidades decorrentes de fenômenos da natureza, porém há ainda quem aposte na sorte em não estar na próxima rota, seja de um tornado, enchente ou até mesmo da ausência de água potável.

Ribeiro (2001, p. 4-5) ressalta que “a ideia de segurança ambiental global não está configurada como um conceito que leva à ação, mas sim à implementação de estratégias por uma unidade política”. Villa (1997, p. 209) salienta que "a singularidade da segurança global multidimensional é que conflitos que podem derivar dos fenômenos transnacionais não admitem a guerra como meio de solução.” Isto é, a problemática ambiental é transnacional e por isso enseja soluções cooperativas e que não admitem o uso da força, porque seria ineficaz para as partes.

Barros-Platiau et al. (2004, p. 102), ao discorrer sobre a crise ambiental, detecta que os "os problemas que constituem esta crise perpassam fronteiras tradicionais e demandam uma ação conjunta de todos os atores envolvidos”. Alerta ainda, para o fato de que as abordagens regionais ou em bloco tem sido as melhores vias para soluções, pois evitam entraves e impedimentos encontrados na cooperação internacional para a governança ambiental (BARROS-PLATIAU et al., 2004).

Pensar o meio ambiente e como as dinâmicas globais foram, são e serão condicionadas a partir de suas mudanças, é sobretudo ter a clareza que sua característica sistêmico-complexa não só traz intrínseca a relação necessária entre homem e a natureza, mas principalmente determina como a economia, saúde, segurança entre outros fatores estruturais de uma sociedade podem, ou não, existir. A geopolítica global, e em específico a ambiental, tem apontado na direção cada vez maior de conflitos por recursos naturais. Nesse cenário, aos países detentores de grande sociobiodiversidade como os países amazônicos, cabe predizer os movimentos dessa dinâmica e agir propositivamente para fomentar o desenvolvimento e ampliação de mecanismos de cooperação estratégica regional para a defesa do meio ambiente. Importante organizar e visualizar os diferentes atores (locais, regionais e globais) em um mesmo tabuleiro geográfico e conceitual, para assim primar pelos elementos objetivos (interdependência e sobrevivência) e menos pelos subjetivos e ideológicos (TUATHAIL et al., 2003).

É dentro dessa estrutura de busca pela efetiva segurança e paz regional que se encontra a OTCA e é a partir da sua essência e finalidades, bem como da relação de interdependência entre seus signatários, que as soluções conjuntas devem emergir. Isso porque a complexidade do pensamento geopolítico demonstra que, 
face à impossibilidade de desvincular o debate político dos espaços e a clara simbiose entre a geopolítica e a geoeconomia, é inegável que o alcance a recursos como água, alimentos, energia, entre outros, podem ser mediados por acesso regulado por comércio, com meios pacíficos e regras de jogo pré-estabelecidas, como também podem ser alvo de aquisição por meio da força e ocupação do espaço.

Nesse aspecto, o reforço à cooperação estratégica em matéria ambiental e ao fortalecimento da região quantos a esses mecanismos apontam para a necessidade de retomada do multilateralismo, de modo a guiar-se por princípios como: a) pluralismo, onde os sistemas de governança nacional, regional e global trabalham em conjunto e não existam regimes de sobreposição, mas sim de equilíbrio; b) fortalecimento dos processos multilaterais e fortalecimento das organizações internacionais; c) bem como uma maior responsabilização dos governos por meio de regimes de accountability $^{2}$ (WOODS et al., 2013). Como afirmou o Secretário Geral das Nações Unidas, António Guterres, a renovação do compromisso com o multilateralismo se faz primordial em tempos em que, embora o mundo esteja mais conectado, as sociedades estão mais fragmentadas, as relações de poder se mostram cada vez menos claras, os valores universais, os princípios democráticos e o Estado democrático de direito têm sido minados. Assim, diante de problemas como as alterações climáticas, tensões geopolíticas e as crises decorrentes, são necessárias ações e políticas coletivas capazes de transcender as fronteiras nacionais (ECOSOC, 2018).

A ocupação dos espaços está condicionada às necessidades que os fluxos contemporâneos requerem. Seja a necessidade de recursos essenciais à vida ou estratégicos para a maximização de ganhos e poder. Nesse sentido, a paisagem é transformada pela ação do homem. Daí a importância em pensar o espaço transformado pela política, pois na medida em que as sociedades redesenham suas interações e objetivos, novas leituras geopolíticas são redefinidas. Diante da breve síntese, vale chamar atenção para o fato de que o realismo adotado nos cenários de governança global não permite ignorar essas dinâmicas, pelo que se entende como melhor alternativa, conhecer melhor os instrumentos para ter condições de avaliar em que medida uma ou outra decisão auxilia pensar o problema da guerra e aponta caminhos para a paz.

\section{Considerações finais}

A complexidade que envolve os processos de securitização e dessecuritização da questão ambiental demonstra que a proteção da sociobiodiversidade da Amazônia pressupõe estratégias que possam convergir os interesses nacionais e os regionais. O Conselho de Defesa Sul-Americano, ainda que não tenha recebido a devida importância, poderia ser tido como uma iniciativa apta para fomentar e desenvolver a formação de um complexo regional de segurança.

Contudo, verifica-se que as expressões de acordos regionais ainda se restringem às agendas globais (Guerra ao Terror e guerra às drogas) e não apresentam grandes preocupações e/ou percepções de ameaças com relação a situações específicas, como a proteção e defesa da sociobiodiversidade. Como aventado, o

\footnotetext{
${ }^{2}$ Rached (2016) em The Concept(s) of Accountability: Form in Search of Substance 2 , elucida accountability como uma ferramenta de controle do processo decisório, isto é, mecanismo capaz de restringir a autonomia de organismos internacionais, a fim de estabelecer um elo entre aquele que toma a decisão (power holder) e aquele que sofre os efeitos desta (account holder). Além é claro, de atender os devidos regimes de accountability, devem poder ponderar suas necessidades, características e peculiaridades, de maneira que as políticas sejam pensadas, discutidas, elaboradas e executadas de forma conjunta e cooperativa.
} 
tratamento da questão ambiental sob a perspectiva regional e de segurança pretende demonstrar a importância do regionalismo nesse esforço, em especial entre países que têm elementos em comum: a sociobiodiversidade e a necessidade de sua preservação e defesa.

A construção de um complexo de segurança regional e o reforço aos mecanismos de cooperação estratégica como a OTCA, devem ser prioridades para a região Sul-Americana. Com auxílio de uma política externa brasileira que vise a integração do continente e projeção internacional a partir da proteção da sociobiodiversidade da Amazônia. E assim, possa retomar a tradição global-multilateral e a posição de paymaster da qual o Brasil nunca devia ter se afastado.

A securitização ambiental não pode ser vista apenas como vetor de segurança e instrumento facilitador de ingerências de grandes potências e organismos internacionais. Deve sim, ser a mola propulsora para o desenvolvimento de movimentos e concertos regionais no sentido de fomentar mecanismos estratégicos e eficazes na defesa e proteção da sociobiodiversidade. Organizações internacionais são pensadas por seus soberanos no sentido de reduzir os custos das transações, inspirar regras e dinâmicas, cumprem o papel de mediadoras e reguladoras das relações entre os Estados em suas necessidades de comércios, fluxos de pessoas, bens e serviços. A OTCA oferece esse espaço de diálogo e construção de soluções conjuntas, de modo a atender às necessidades dos países amazônicos diante da atual geopolítica ambiental, permeada por movimentos de ingerência ecológica e corrida por recursos naturais.

Abordar a temática é de grande relevância no contexto de justaposição de atores e agendas, que a cada dia apresentam mecanismos de projeção de poder e que se reinventam a cada nova ameaça de mudança estrutural e reorganização do equilíbrio de poder no sistema internacional. Os países amazônicos devem ser protagonistas na gestão da Amazônia, desde as suas políticas públicas internas e externas, até na responsabilidade pela manutenção da paz e segurança regional.

\section{REFERÊNCIAS}

AYOOB, Mohammed. From Regional System to Regional Society: Exploring Key Variables in the Construction of Regional Order - Australian Journal of International Affairs. Vol.53, N.3, 1999.

ARAUJO, Luiz Ernani Bonesso de. O Direito da Sociobiodiversidade. In Direitos emergentes na sociedade global: anuário do programa de pós-graduação em direito da UFSM. Organizador Jerônimo Siqueira Tybusch, Luiz Ernani Bonesso de Araujo e Rosane Leal da Silva. v 1. p. 271-291. Unijuí-RS. Ed. Ijuí, 2013.

ARON, Raymond. Paz e guerra entre as nações. Brasília: Ed. UnB, 2006.

BACHELET, Michel. Ingerência Ecológica: Direito Ambiental em questão. Lisboa: Instituto Piaget, 1995.

BARROS-PLATIAU, Ana Flávia; VARELLA, Marcelo Dias; SCHLEICHER, Rafael T. Meio ambiente e relações internacionais: perspectivas teóricas, respostas institucionais e novas dimensões de debate. Revista Brasileira de Política internacional, Brasília, v. 47, n. 2, p. 100-130, 2004. Disponível em: <http://www.scielo.br/pdf/rbpi/v47n2/v47n2a04.pdf>. Acesso em 01 set. 2019.

BECKER, Bertha K. Amazônia: Geopolítica na virada do III milênio, Rio de Janeiro: Garamond, 2007.

BECKER, Bertha. K. A geopolítica na virada do milênio: logística e desenvolvimento sustentável. In: CASTRO, I. E.; GOMES, P. C. C.; CORRÊA, R. L. (Orgs.). Geografia: conceitos e temas. Rio de 
Janeiro: Bertrand Brasil, 1995.

BOENO, Raul Kleber de Souza; BOENO, Renate Kottel; MARQUES, Viriato Soromenho. Alterações Climáticas e Securitização: a construção da dissuasão climática. Coleção Meira Mattos, Rio de Janeiro, v. 9, n. 36, p. 595-605, set./dez. 2015. Editora ECEME. Escola de Comando e Estado Maior do Exército. Disponível em: $<$ http://repositorio.ul.pt/bitstream/10451/22441/1/ICS_Boeno_Alteracoes_ARI.pdf >. Acesso em 15 abr. 2019.

BUZAN, Barry; HANSEN, Lene. A evolução dos estudos de segurança internacional. Tradução Flávio Lira. São Paulo: Ed. Unesp, 2012.

BRUCKMAN, Monica. Recursos naturales y la geopolítica de la integración sudamericana. Quito: Instituto de Altos Estudios Nacionales, 2012.

CABRERA, Lester Toledo. Geopolítica en América del Sur: desde la militarización de la disciplina a la necesidad del debate académico. Revista Chilena de Derecho y Ciencia Política, v. 8. n. 2, 2017. p.167-188. Disponível em: <https://dialnet.unirioja.es/servlet/articulo?codigo=6379974>. Acesso em 10 mai. 2019.

CABRERA, Lester Toledo. La construcción de la geopolítica en suramérica: puntos de encuentro y desencuentro de una disciplina relegada. Anal. Polit. Bogotá, v. 31, n. 94, p. 175-192, Dec. 2018. Disponível em: $\quad<$ http://www.scielo.org.co/scielo.php?script=sci_arttext\&pid=S0121$47052018000300175 \& \operatorname{lng}=$ en $\& n r m=$ iso $>$. Acesso em 10 mai. 2019.

CUNHA E MENEZES, Pedro de Castro da. Áreas de preservação ambiental em zona de fronteira: sugestões para uma cooperação internacional no contexto da Amazônia. Brasília. FUNAG, 2015.

ECOSOC. Renovando o Compromisso com o Multilateralismo: Um Diálogo de Alto Nível dos Presidentes da Assembleia Geral, ECOSOC, o Conselho de Segurança e o Conselho de Direitos Humanos 31 de outubro de 2018, 1: 15-14: 30, Câmara do ECOSOC, UNHQ, Novo Iorque.

FUCCILLE, Luís Alexandre; RESENDE, Lucas Pereira. Complexo de Segurança Regional da América do Sul: uma nova perspectiva. Contexto Internacional, Rio de Janeiro, v. 35, n. 1, p. 77-104, Junho de 2013. Disponível em: <http://www.scielo.br/scielo.php?script=sci_arttext\&pid=S0102$85292013000100003 \& \operatorname{lng}=e n \& n r m=$ iso>. Acesso em 10 mai. 2019.

FUCCILLE, Luís Alexandre; BRAGATTI, Milton Carlos; LEITE, Maria Luísa Telarolli de Almeida. Geopolítica dos Recursos Naturais na América do Sul: um panorama dos recursos hídricos sob a ótica da Segurança Internacional | Geopolitics of Natural Resources in South America: a panorama of water resources under the view. Mural Internacional, [S.1.], v. 8, n. 1, p. 59-75, jun. 2018. ISSN 21777314. Disponível em: <https://www.epublicacoes.uerj.br/index.php/muralinternacional/article/view/32569>. Acesso em 01 set. 2019.

GEHRE, Thiago. O Brasil e a agenda ambiental no século 21: clima, energia e segurança. Revista Múltipla, Brasília, v. 21, n. 27, p. 69-94, dezembro - 2009. Disponível em: < https://upis.br/biblioteca/pdf/revistas/revista_multipla/multipla27.pdf> Acesso em 01 set. 2019.

HURREL, Andrew. One world? Many worlds? The place of Regions in the Study of International Society. International affairs, v. 83, n.1, pp.127-146, 2007. Disponível em: <https://academic.oup.com/ia/article-abstract/83/1/127/2435051/?redirectedFrom=fulltext>. Acesso em 10 jun. 2019.

LIMA, M. R. S. de. A Aspiração internacional e política externa. Revista Brasileira de Comércio Exterior, Rio de Janeiro, ano XIX, n. 82, p. 4-19, jan./mar. 2005. Disponível em: <http://www.funcex.org.br/publicacoes/rbce/material/rbce/82-MRSL.pdf>. Acesso em 05 jun. 2019. 
MIYAMOTO, Shiguenoli. AMAZÔNIA: meio ambiente, fronteiras e segurança. Campinas: IFCH, UNICAMP, 2010.

RACHED, D.H. 'The Concept(s) of Accountability: Form in Search of Substance', Leiden Journal of International Law, 29(2), pp. 317-342, 2016. Disponível em: $<$ https://www.cambridge.org/core/journals/leiden-journal-of-international-law/article/theconcepts-of-accountability-form-in-search-ofsubstance/8E481D883DC5B5E9752C3CCA9BE39884\#>. Acesso em 26 mai. 2019.

RESK, Sucena Shkrada. A carência de uma visão e ação integradas panamazônicas. In EcoDebate, ISSN 2446-9394, Mangaratiba-RJ, 29/08/2019. Disponível em: <https://www.ecodebate.com.br/2019/08/29/a-carencia-de-uma-visao-e-acao-integradaspanamazonicas-por-sucena-shkrada-resk/>. Acesso em 01 set. 2019.

RIBEIRO, Wagner Costa. Desenvolvimento sustentável e segurança ambiental global. Biblio 3W, Revista Bibliográfica de Geografía y Ciencias Sociales. v. 6, n. 312, p. 1-8, 2001. Disponível em: < http://www.ub.edu/geocrit/b3w-312.htm>. Acesso em 01 set. 2019.

RIBEIRO, Wagner Costa. A ordem ambiental internacional. São Paulo: Contexto, 2001.

SOARES DE LIMA, Maria Regina. MILANI, Carlos R.S. DUARTE, Rubens de S. ALBUQUERQUE, Marianna R. A. de. ACÁCIO, Igor D.P. CARVALHO, Tássia C. MEDEIROS, Josué. NOVACEK, Niury. COSTA, Murilo Gomes da. COSTA, Hugo Bras M. da. LEMOS, Juliana P. Prefácio de Celso Amorim. Atlas da política brasileira de defesa. $1^{\mathrm{a}}$ ed. - Ciudad Autónoma de Buenos Aires: CLACSO; Rio de Janeiro: Latitude Sul, 2017.

PECEQUILO, Cristina Soreanu. A política externa do Brasil no século XXI: os eixos combinados de cooperação horizontal e vertical. Revista Brasileira de Política Internacional. Brasília, v. 51, n.2, p. 136-156, dezembro de 2008. Disponível em: <http://www.scielo.br/scielo.php?script=sci_arttext \&pid=S003473292008000200009\&lng=en\&nrm=iso>. Acesso em 10 mai. 2019.

RODRIGUES, Thiago. Narcotráfico e Militarização nas Américas: vício de guerra. Contexto Internacional, v. 34, n. 1, p. 9-41, junho de 2012. Disponível em: $<$ http://www.scielo.br/scielo.php?script=sci_arttext\&pid=S0102$85292012000100001 \& \operatorname{lng}=e n \& n r m=i s o>$. Acesso em 05 jun. 2019.

RODRIGUES, Gilberto Marcos Antonio. A Amazônia como foco da integração: a convergência entre a UNASUL e a OTCA. Revista Extraprensa (USP), v.7, n.1, p. 54-61, 2013. Disponível em: <http://www.revistas.usp.br/extraprensa/article/view/77279>. Acesso em 01 set. 2019.

SARAIVA, Miriam Gomes. Integração regional na América do Sul: processos em aberto. In: $3^{\circ}$ ENCONTRO NACIONAL ABRI 2011, 3. 2011, São Paulo.

SAINT-PIERRE, Hector Luís. 'Defesa' ou 'Segurança'? Reflexões em torno de Conceitos e Ideologias. Contexto Internacional. Rio de Janeiro, v. 33, n. 2, p. 407-433, dezembro de 2011. Disponível em: $<$ http://www.scielo.br/scielo.php?script=sci_arttext\&pid=S010285292011000200006\&lng=en\&nrm=iso>. Acesso em 03 mar. 2019.

SAINT-PIERRE, Hector Luís; DA SILVA, Diego. A Torre de Babel Sul-Americana: a importância da convergência conceitual para a cooperação em defesa. In: CARMO, Corival Alves do. WINAND, Érica C. A. BARNABÉ, Israel Roberto. PINHEIRO, Lucas Miranda (Org.). Relações Internacionais: Olhares Cruzados. p. 281-314, Brasília: FUNAG, 2013.

SANTOS, Leandro Fernandes Sampaio. A Amazônia como Instrumento da Política Externa Brasileira. Revista Aurora, Marília, v. 7 n. 2, p. 109-122, Jan-Jun, 2014. Disponível em: <http://www2.marilia.unesp.br/revistas/index.php/aurora/article/view/3854>. Acesso em 01 jun. 
2019.

SOUZA, Elany Almeida de. Perspectivas Regionais para a Defesa da Soberania Ambiental: uma análise dos documentos de Defesa brasileiros e parcerias regionais para a proteção da biodiversidade. In ABED - Associação Brasileira de Estudos de Defesa Volume 1. $1^{\text {a }}$ Edição Novembro de 2018. Anais do $10^{\circ}$ Encontro Nacional da Associação Brasileira de Estudos de Defesa FFLCH/USP São Paulo, 2018. Disponível em: <https://www.enabed2018.abedef.org/resources/anais/8/1534727367_ARQUIVO_PERSPECTIVASR EGIONAISPARAADEFESADASOBERANIAAMBIENTAL.pdf>. Acesso em 20 jun. 2019.

SOUZA, Elany Almeida de. Defesa da soberania ambiental do brasil: a desconstrução da retórica da securitização como instrumento de afirmação do poder no cenário internacional. Anais do $4^{\circ}$ Seminário de Relações Internacionais, Universidade Federal da Integração Latino-Americana (UNILA), $2018 . \quad$ Disponível em: $<$ https://www.seminario2018.abri.org.br/site/anaiscomplementares2?AREA=1\#E >. Acesso em 20 jun. 2019.

SOUZA, Elany Almeida de. PINTO, Danielle Jacon Ayres. SOUZA, Mariana de Castro Silva. Variáveis relevantes na proteção da biodiversidade da Amazônia: securitização, regionalismo e defesa. In: O lugar da Amazônia nas Relações Internacionais: novas abordagens. Whitney Cabral e Daniel Chaves (orgs.) Macapá, Editora da Unifap, 2017. Disponível em: <https://www2.unifap.br/editora/files/2018/12/O-lugar-da-Amaz\%c3\%b4nia-nasrela\%c3\%a7\%c3\%b5es-internacionais.pdf >. Acesso em 20 jun. 2019.

STRITZEL, Holger. Towards a Theory of Securitization: Copenhagen and Beyond. European Journal of International Relations. Vol. 13, $\mathrm{n}^{\mathrm{o}}$ 3, p. 357-383, September 2007. Disponível em: <https://journals.sagepub.com/doi/10.1177/1354066107080128>. Acesso em 10 mai. 2019.

TANNO, Grace. A Contribuição da Escola de Copenhague aos Estudos de Segurança Internacional. Rio de Janeiro: Contexto Internacional. Vol. 25, $\mathrm{n}^{\circ}$ 1, p. 47-80, janeiro/junho 2003. Disponível em: <http://www.scielo.br/pdf/cint/v25n1/v25n1a02.pdf>. Acesso em 12 mar. 2019.

TICKNER, A.; HERTZ, M. No Place for Theory? Security Studies in Latin America. In: A. Tickner y D. Blaney (eds.). Thinking International Relations Differently, p. 92-114. Nueva York: Routledge, 2012.

TUATHAIL, Gearóid Ó; DALBY, Simon and ROUTLEDGE, Paul. The Geopolitics Reader. Taylor \& Francis e-Library, 2003.

TUCÍDIDES (c. 460 - c. 400 a. C) T532h História da Guerra do Peloponeso/Tucídides; Prefácio de Helio Jaguaribe; Trad. do grego de Mário da Gama Kury. - $4^{\text {a }}$ edição - Brasília: Editora Universidade de Brasília, Instituto de Pesquisa de Relações Internacionais; São Paulo: Imprensa Oficial do Estado de São Paulo, XLVII, 584 p., 23 em -(Clássicos IPRI, 2), 2001.

URT, João Nackle; PINHO, Alexandre Felipe. Securitização e dessecuritização da Amazônia contemporânea. Meridiano 47, Journal of Global Studies v. 11, n. 114, p. 34 a 35, jan. 2010. Disponível em: <http://periodicos.unb.br/index.php/MED/article/view/3940> Acesso em 10 abri. 2019.

WÆVER, Ole; BUZAN, Barry; e WILDE, Japp de. Security: a New Framework for Analysis. Londres: Lynne Rienner Publishers, 1998.

WOODS, Ngaire; BETTS, Alexander, PRANTL, Jochen, SRIDHAR, Devi. Transforming Global Governance for the 21st Century. 2013. Disponível em: <http://hdr.undp.org/sites/default/files/hdro_1309_woods.pdf.>. Acesso em 01 jun. 2019.

VILLA, Rafael Antonio Duarte. Da crise do realismo à segurança global multidimensional. Tese de Doutorado (Ciência Política) São Paulo: FFLCH/USP, 1997. 
VILLA, Rafael Antonio Duarte. FOLs: as novas formas de operacionalização da presença militar estadunidense na América do Sul. Carta Internacional, v. 8, n. 1, p. 75-90, 2013. Disponível em: <https://cartainternacional.abri.org.br/Carta/article/view/80> Acesso em 04 mar. 2019.

VILLA, Rafael Antonio Duarte. O Paradoxo da Macrossecuritização: Quando a Guerra ao Terror não Securitiza Outras "Guerras” na América do Sul. Contexto Internacional. Rio de Janeiro, v. 36, n. 2, p. 349-383, $2014 . \quad$ Disponível em: $<$ http://www.scielo.br/scielo.php?script=sci_arttext\&pid=S0102$85292014000200349 \& \operatorname{lng}=$ en \&nrm=iso $>$. Acesso em 20 mar. 2019. 


\title{
RESUMO
}

A securitização ambiental tem despertado discussões em âmbito global e, em razão desse aspecto macro, nem sempre questões regionais são devidamente consideradas. Nesse sentido, questiona-se: um complexo regional de segurança sul-americano pode ser eficiente e eficaz em reunir agendas aptas à proteção da sociobiodiversidade? Pretende-se investigar a existência de mecanismos e estratégias de Defesa regionais capazes de compreender os processos de securitização e, sobretudo, os interesses que envolvem as discussões ambientais no cenário internacional. A criação da dimensão regional de defesa em matéria ambiental é essencial para a formação de um pensamento autônomo e estratégico de Defesa, dada a relevância geoestratégica, geopolítica e geoeconômica da Amazônia. Partindo de uma matriz epistemológica pragmático-sistêmica, dada a relação sistêmico-complexa que envolve o tema, adota-se para melhor compreensão, uma abordagem de pesquisa interdisciplinar, bibliográfica e documental. Demonstrou-se ao final que a formação de um Complexo Regional de Segurança na América do Sul apresenta-se como uma possibilidade de reunir agendas semelhantes em um concerto de vontades capazes de produzir normas e acordos que atendam às necessidades endógenas da região em matéria ambiental, valendo-se de fóruns de diálogo como a Organização do Tratado de Cooperação Amazônica/OTCA e de mecanismos como o Conselho de Defesa Sul-Americano.

Palavras-chave: Geopolítica Ambiental; Organização do Tratado de Cooperação Amazônica-OTCA; Complexo Regional de Segurança.

\begin{abstract}
Environmental securitization has sparked global discussions and because of this macro aspect, regional issues are not always properly considered. In this sense, the question is: can a South American regional security complex be efficient and effective in putting together agendas suitable for the protection of socio-biodiversity? The aim is to investigate the existence of regional defense mechanisms and strategies capable of understanding securitization processes and, above all, the interests that involve environmental discussions on the international scene. The creation of the regional defense dimension in environmental matters is essential for the formation of an autonomous and strategic defense thought given the geostrategic, geopolitical and geoeconomic relevance of the Amazon. Based on a pragmatic-systemic epistemological matrix, given the systemic-complex relationship that surrounds the theme, an interdisciplinary, bibliographical and documentary research approach is adopted for better understanding. In the end it was demonstrated that the formation of a Regional Security Complex in South America presents itself as a possibility to bring together similar agendas in a concert of wills capable of producing norms and agreements that meet the region's endogenous environmental needs, using dialogue forums such as the Amazon Cooperation Treaty Organization /ACTO and mechanisms such as the South American Defense Council.
\end{abstract}

Key-words: Environmental Geopolitics; Organization of the Amazon Cooperation Treaty-ACTO; Regional Security Complex. 


\section{COPYRIGHT:}

Este é um artigo publicado em acesso aberto e distribuído sob os termos da Licença de Atribuição Creative Commons, que permite uso irrestrito, distribuição e reprodução em qualquer meio, desde que o autor e a fonte originais sejam creditados.

This is an open-access article distributed under the terms of a Creative Commons Attribution License, which permits unrestricted use, distribution, and reproduction in any medium, provided that the original author and source are credited.

\section{(c)

